Carlo Carcasci

Assistant Professor

Department of Industrial Engineering,

University of Florence,

Florence 50139, Italy

e-mail: carlo.carcasci@htc.de.unifi.it

\section{Bruno Facchini}

Associate Professor

Department of Industrial Engineering,

University of Florence,

Florence 50139, Italy

e-mail: bruno.facchini@htc.de.unifi.it

\author{
Marco Pievaroli ${ }^{1}$ \\ Department of Industrial Engineering, \\ University of Florence, \\ Florence 50139, Italy \\ e-mail: marco.pievaroli@htc.de.unifi.it

\section{Lorenzo Tarchi} \\ ERGON Research s.r.l., \\ Florence 50127, Italy \\ e-mail: Iorenzo.tarchi@ergonresearch.it \\ Alberto Ceccherini \\ GE Oil \& Gas, \\ Florence 50127, Italy \\ e-mail: Alberto.Ceccherini@ge.com

\section{Luca Innocenti} \\ GE Oil \& Gas, \\ Florence 50127, Italy \\ e-mail: Luca1.Innocenti@ge.com
}

Heat Transfer and Pressure Loss Measurements of Matrix Cooling Geometries for Gas Turbine Airfoils

\begin{abstract}
Matrix cooling systems are relatively unknown among gas turbines manufacturers of the western world. In comparison to conventional turbulated serpentines or pin-fin geometries, a lattice-matrix structure can potentially provide higher heat transfer enhancement levels with similar overall pressure losses. This experimental investigation provides heat transfer distribution and pressure drop of four different lattice-matrix geometries with crossing angle of $45 \mathrm{deg}$ between ribs. The four geometries are characterized by two different values of rib height, which span from a possible application in the midchord region up to the trailing edge region of a gas turbine airfoil. For each rib height, two different configurations have been studied: one having four entry channels and lower rib thickness (open area 84.5\%), one having six entry channels and higher rib thickness (open area $53.5 \%)$. Experiments were performed varying the Reynolds number Re $e_{s}$, based on the inlet subchannel hydraulic diameter, from 2000 to 12,000. Heat transfer coefficients (HTCs) were measured using steady state tests and applying a regional average method; test models have been divided into 20 stainless steel elements in order to have a Biot number similitude with real conditions. Elements are 10 per side, five in the main flow direction, and two in the tangential one. Metal temperature was measured with embedded thermocouples, and 20 thin-foil heaters were used to provide a constant heat flux during each test. A specific data reduction procedure has been developed so as to take into account the fin effectiveness and the increased heat transfer surface area provided by the ribs. Pressure drops were also evaluated measuring pressure along the test models. Uniform streamwise distributions of Nusselt number $N u_{s}$ have been obtained for each Reynolds number. Measurements show that the heat transfer enhancement level $N u_{s} / N u_{O}$ decreases with Reynolds but is always higher than 2. Results have been compared with previous literature data on similar geometries and show a good agreement.
\end{abstract}

[DOI: 10.1115/1.4028237]

\section{Introduction}

One way of increasing both thermal efficiency and power output of gas turbines is to increase the turbine inlet temperature (TIT) that, in the current advanced engines, can be as high as $1500{ }^{\circ} \mathrm{C}$. Since this temperature is far higher than the melting point of the airfoils material, gas turbines blades and vanes require efficient cooling systems. To ensure the best cooling efficiency, the cooling systems must be designed to minimize the amount of cooling air extracted from the compressor and to achieve the maximum benefits of the highest inlet gas temperature. An efficient cooling system should allow to reach the highest HTCs with the lowest pressure losses and the lowest coolant consumption. Then, the resulting surface temperatures must be compatible with the maximum thermal stress in order to ensure the maximum lifetime of the components.

Gas turbine airfoils usually employ a combination of internal and external cooling arrangements. The internal cooling systems remove the heat conducted from the outside surface, while the external cooling configurations allow to form a protective layer between the outside surface and the hot gas path flow.

In regards to internal techniques, cooling air flows through internal passages inside the airfoil cross section that are usually turbulated to increase the heat transfer by increasing the heat transfer

\footnotetext{
${ }^{1}$ Corresponding author.

Contributed by the International Gas Turbine Institute (IGTI) of ASME for publication in the Journal of TURBOMACHINERY. Manuscript received July 11, 2014; final manuscript received July 24, 2014; published online August 26, 2014. Editor: Ronald Bunker.
}

area and the flow turbulence. Different cooling schemes must be used in different regions of the airfoil depending on the thermal load and mechanical strength requirements. The leading edge is generally cooled by jet impingement, the trailing edge is cooled by pin fins, while serpentine passages with rib turbulators are usually applied to cool the middle portion of the gas turbine airfoils.

An interesting alternative cooling technique is the latticeworkmatrix cooling. Compared to the above mentioned solutions, a lattice-matrix geometry provides a greater structural rigidity and a higher heat transfer enhancement with similar pressure losses.

Latticework or matrix cooling originated within the Soviet design system about 30 years ago. The application of latticework-matrix structures within blades and vanes of Soviet designs has occurred simultaneously with the use of serpentine ribbed channels and pin-fin arrays of the Western world. Figure 1 shows an example of lattice cooled blade and a detailed view of the flow along a subchannel.

A matrix cooling system is mainly composed by two layers of longitudinal ribs with an opposite angle of inclination $\beta$ forming a system of crossing subchannels. These two layers are representative of pressure and suction sides of a gas turbine airfoil. The cooling air enters the matrix and flows both in the lower and higher half of the structure; the air that reaches the dead-end of the side wall flows through the bend and into the subchannel on the opposite layer with little or no mixing with the air from the other layer. Each time the flow hits the side wall it has to turn by the angle $2 \beta$ switching from a pressure side subchannel to a suction side subchannel or vice versa. When the flow passes from one subchannel to another, a swirl motion is created and the 


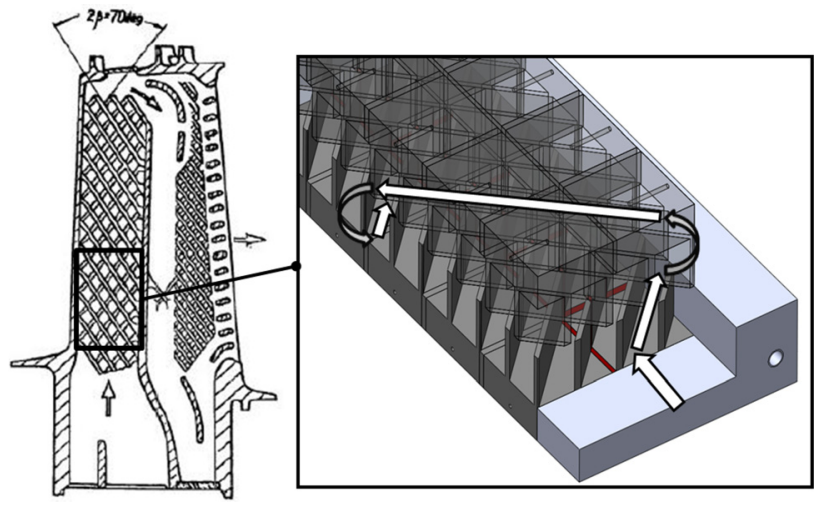

Fig. 1 Example of lattice cooled blade [1] and schematic of subchannel flow

turbulence of the flow is increased; this increases the HTC. Moreover, the flow turbulence in each subchannel is increased by interaction with the cross flow. Heat transfer is also increased due to the high heat transfer surface area provided by the longitudinal ribs of the whole lattice-matrix structure.

The longitudinal ribs, which intersect each other from the two opposite layers, offer several benefits such as: an improved structural strength, an improved heat transfer and an uniform heat transfer distribution along cooling subchannels both axially and laterally.

The benefits of matrix cooling systems have been investigated by some experimental studies, which are not fully available in the open literature and only few of them have been published. About 20 years ago, Goreloff et al. [1] measured HTCs on lattices with different inclinations of ribs (from 30 to $120 \mathrm{deg}$ ) using the molten zinc solidification process. Compared to a smooth passage, these results proved that the greatest heat transfer enhancement occurs at $35 \mathrm{deg}$ over a range of Reynolds number from 5000 to 20,000. Nagoga [2] also investigated heat transfer on different inclinations of matrix channels; his results show that the average heat transfer enhancement is in the range of 2-3.1 for several inclination angles between ribs, but the best heat transfer performance is obtained at $45 \mathrm{deg}$ to the flow direction. At present, Nagoga's work is the only that contains heat transfer and friction correlations for lattice-matrix geometries; these correlations and their ranges are also reported by Sundberg [3].

Some years later, Gillespie et al. [4] applied a transient liquid crystal technique to measure local HTC distributions in a lattice cooling model representing a trailing edge system of a high pressure rotor blade with flow ejection through film cooling holes. From this study, it was found that the reduction of cooling potential is due to the flow velocity decrease from root to tip of the blade as coolant is bled off to the film cooling holes.

A detailed investigation on HTCs and pressure losses in lattice-matrix channels was carried out by Bunker [5] over a range of Reynolds number from 20,000 to 100,000 . Two different methods were applied to determine the local and overall HTCs for ribs with an inclination angle of $45 \mathrm{deg}$. Some interesting effects were investigated such as: different number of subchannels, turning of the flow at the side walls and fin enhancement provided by the ribs. A steady liquid crystal technique with acrylic model and insulating ribs was applied to determine heat transfer on primary surfaces that represent the pressure and suction side walls of an airfoil. On the other hand, a transient infrared thermographic method with metallic model and metal ribs was used to evaluate the additional heat transfer impact provided by the fin effectiveness of the ribs. Compared to smooth passages the heat transfer enhancement level on primary surfaces is about 1.5 , but has local peaks of about 3 after each turn at a subchannel dead end. The results obtained from metallic model transient tests include both the primary surface and rib surface heat transfer and show overall enhancement values from 2.5 to 3 . These experimental results also showed that the matrix geometry with fewer subchannels provided higher values of heat transfer enhancement.

Saha et al. [6,7] studied the heat transfer augmentation and pressure drop in a converging trailing edge matrix structure where ribs are inclined at $45 \mathrm{deg}$ to the flow direction. Two matrix geometries with two and four subchannels were considered and the combination of $90 \mathrm{deg}$ turn of the flow at the entry and a converging cross section was also investigated varying Reynolds number from 4000 to 60,000 . Averaged heat transfer enhancements are in the range of 2-3.5 with the higher values at the lower Re numbers. Moreover pressure drop increases in the streamwise direction and the overall friction factor for the subchannel increases with increasing Reynolds number. According to this study a matrix cooling system has higher HTCs and higher thermal performance factors (TPFs) than pin-fins.

Acharya et al. [8] were the first to experimentally study the effects of channel rotation on heat transfer and pressure drop in a matrix structure. They proved that rotation affects heat transfer distributions only for Reynolds numbers lower than 10,000, while no significant rotation effects are observed on friction factors. Oh et al. [9] also investigated the heat transfer and pressure drop characteristics under rotating conditions; the heat/mass transfer rates on the leading and trailing surfaces were measured using a naphthalene sublimation method.

From this literature survey comes out that the heat transfer has been investigated mainly on primary surfaces and only few studies also evaluate the heat transfer on the rib surfaces. In fact, the contribution of rib surfaces, which act as fins, is important in the overall heat transfer estimation because of fin effectiveness and additional heat transfer surface.

The first objective of the present experimental study is to evaluate HTCs on different matrix geometries taking into account the fin effectiveness and the increased heat transfer surface area provided by the ribs; to reach this goal, a specific data reduction procedure has been developed. Another objective of this study is to find the heat transfer performance of matrix cooling geometries in a condition of Biot number similitude as close as possible to that of a real application. For this reason, a specific stainless steel (AISI 304) has been selected for the test models. Heat transfer and pressure drop measurements have been performed varying the Reynolds number from 2000 to 12,000 . The effects of a variation of rib height, rib thickness and number of subchannels have been also investigated.

\section{Experiments}

2.1 Experimental Facility. The experimental survey was performed at the Department of Industrial Engineering (DIEF) of the University of Florence. The test facility as shown in Fig. 2

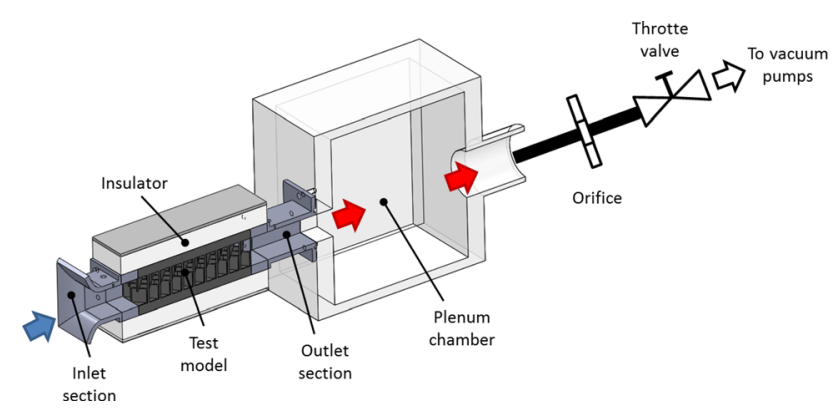

Fig. 2 Test facility 
consists of an open-loop suction type wind tunnel and it is mainly composed by: a test model, a plenum chamber, a vacuum system, a data acquisition system, a pressure scanner, and a DC power supply system.

The air at atmospheric pressure and ambient temperature enters axially into the test rig passing through a shaped inlet section (Fig. 2). Air flow rate is supplied to the test section by using four rotary vane vacuum pumps: two with a capacity of $900 \mathrm{~m}^{3} / \mathrm{h}$ each and two with $300 \mathrm{~m}^{3} / \mathrm{h}$ each. The mass flow rate is controlled by varying the speed of the pumps and using a throttle valve located between the vacuum pumps and the test section.

The mass flow rate is measured according to the standard EN ISO $5167-1$ by means of an orifice located downstream the plenum chamber with a measurement accuracy below $3 \%$.

The flow rate was varied for each test in order to reach the target values of Reynolds number at the inlet of the matrix module and hence at the inlet of the single subchannel.

The inlet and exit flow temperatures are measured with four T-type thermocouples; two are located at the inlet and two at the outlet section of the test model. The metal temperatures of matrix modules are measured with 20 T-type thermocouples; one thermocouple is embedded into the base of each steel block. Thermocouples are connected with a reference junction to a data acquisition/ switch unit (Agilent 34970 A) with a measurement accuracy of $0.5 \mathrm{~K}$.

Twenty Minco Kapton etched foil heaters are applied to the back surface of steel matrix elements to provide a constant heat flux during each test.

A pressure scanner Scanivalve DSA 3217 with temperature compensated piezoresistive relative pressure sensors measure the static pressure in 14 different locations inside the test section with a maximum accuracy of $17 \mathrm{~Pa}$.

2.2 Test Model. The structure of the test model is mainly composed by two halves: a upper module and a lower one. Figure 3 illustrates a top section view of the lower module. Each module consists of an aluminum outer frame and a matrix geometry; the latter is formed by 10 stainless steel (AISI 304 with a thermal conductivity equal to $15.1 \mathrm{~W} / \mathrm{mK}$ ) elements, five in the main flow direction (streamwise), and two in the tangential one (spanwise). The adjacent steel elements are separated from each other by insulation spacers of bakelite with a thermal conductivity close to $0.6 \mathrm{~W} / \mathrm{mK}$. Moreover, an insulation spacer of bakelite is interposed between the aluminum frame and the steel matrix structure (not shown in figure).

The crossing ribs/channels are integrally machined on the steel blocks and the sandwiched insulation spacers. The two halves are

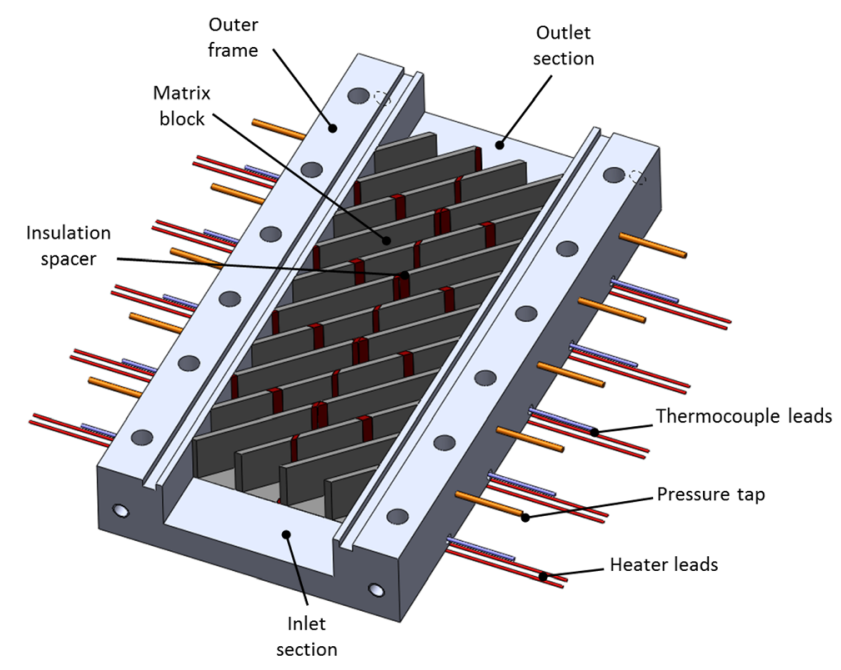

Fig. 3 Test model coupled together so as to oppose each other and cross in a lattice structure; on each half the ribs are oriented at an angle of $45 \mathrm{deg}$ to the streamwise direction.

Some screws through the top and bottom frames run through the holes and are tightened to hold the test section together. O-rings are seated in two grooves realized along the frame borders and are compressed during the assembly of the two parts creating a seal at the interface. A row of through holes is present on each of the two lateral walls of the frames; these holes are aligned to those drilled on the different steel blocks so as to allow the insertion of the thermocouples. Another row of through holes is realized on the same lateral walls to allow the location for the pressure taps.

Figure 4 shows the details of a group of four steel matrix blocks. Between two adjacent blocks an insulation spacer of bakelite is interposed for both streamwise and spanwise directions. Moreover, to avoid that the insulator affects the flow field, the channels have been carefully remachined to reach a flat surface. Each steel block is equipped with a Minco Kapton etched foil heater so as to apply a specific heat flux for each position of the matrix module. Five DC power supplies are used to individually regulate the heat flux of the heaters; each power supply has two outputs and each output provides the same voltage to a couple of heaters that are connected in parallel. According to this arrangement, each streamwise position is identified by two couples of heaters: one for the lower module and one for the upper module.

2.3 Matrix Geometries. Four test geometries, identified by an ID number ranging from 01 to 04 , were investigated with the geometric dimensions shown in Table 1; the geometric parameters

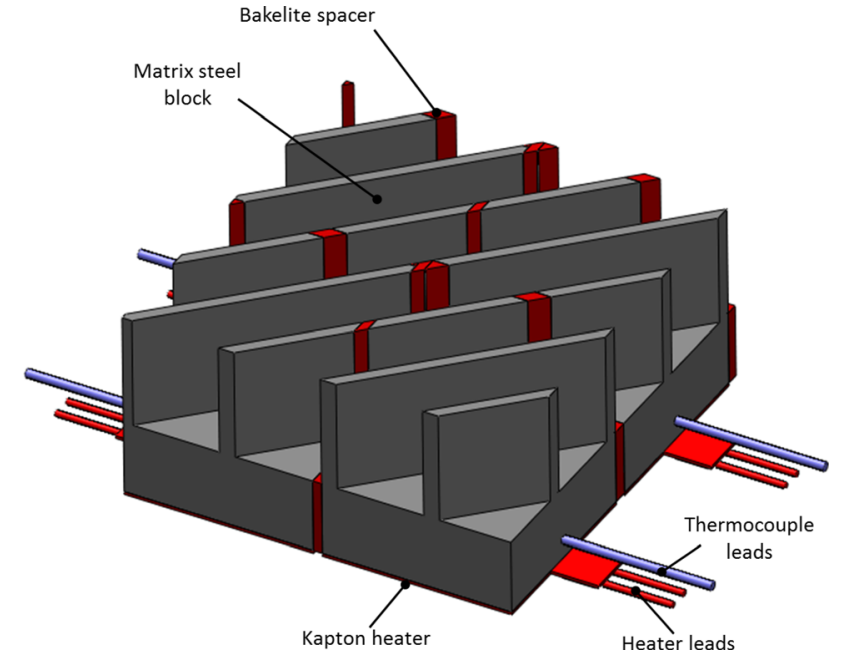

Fig. 4 Matrix blocks

Table 1 Dimensions of test geometries

\begin{tabular}{lccccc}
\hline \hline Geometry & ID & 01 & 02 & 03 & 04 \\
\hline$W$ & $(\mathrm{~mm})$ & 52 & 52 & 52 & 52 \\
$H$ & $(\mathrm{~mm})$ & 30 & 30 & 3 & 3 \\
$L$ & $(\mathrm{~mm})$ & 135 & 135 & 135 & 135 \\
$n_{\text {can }}$ & - & 4 & 6 & 4 & 6 \\
$t_{\text {rib }}$ & $(\mathrm{mm})$ & 1.5 & 3.0 & 1.5 & 3.0 \\
$h_{\text {rib }}$ & $(\mathrm{mm})$ & 15 & 15 & 1.5 & 1.5 \\
$\beta$ & $(\mathrm{deg})$ & 45 & 45 & 45 & 45 \\
$d_{\mathrm{h}, \mathrm{s}}$ & $(\mathrm{mm})$ & 10.59 & 5.62 & 2.54 & 2.09 \\
$W_{\mathrm{c}}$ & $(\mathrm{mm})$ & 8.19 & 3.46 & 8.19 & 3.46 \\
$A . R$. & - & 1.83 & 4.34 & 5.46 & 2.31 \\
$R_{\mathrm{vp}}$ & $(\%)$ & 84.5 & 53.5 & 84.5 & 53.5 \\
$l$ & $(\mathrm{~mm})$ & 73.5 & 73.5 & 73.5 & 73.5 \\
\hline \hline
\end{tabular}



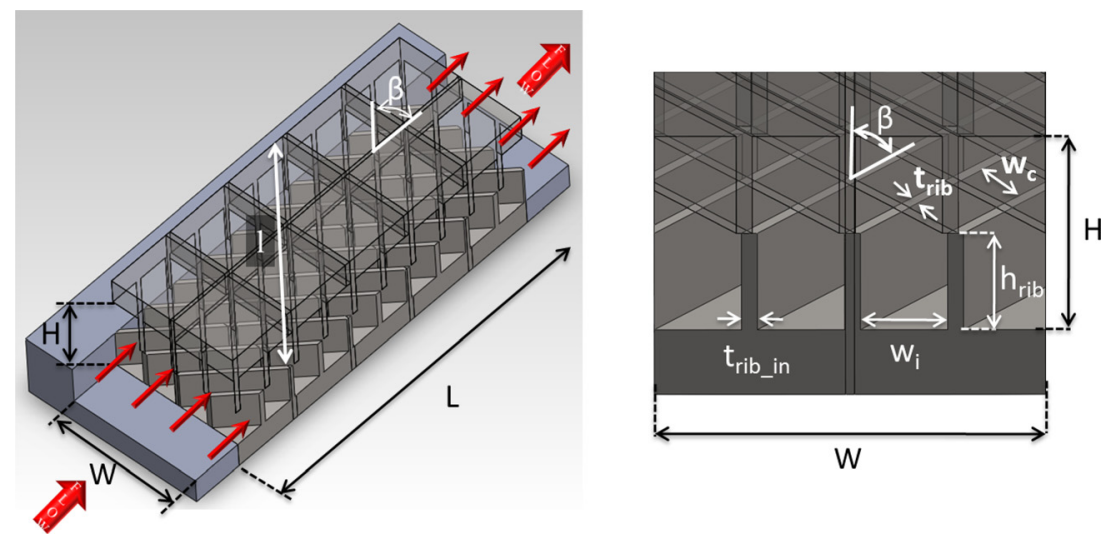

Fig. 5 Geometric parameters of tested matrix geometries

are depicted in Fig. 5. The overall cross section of the test models is the same for (Geom 01, 02) and for (Geom 03, 04) matrix geometries. In the first two cases, the dimensions of the cross section are $W=52 \mathrm{~mm}$ and $H=30 \mathrm{~mm}$, while in the other two cases, the dimensions are $W=52 \mathrm{~mm}$ and $H=3 \mathrm{~mm}$. These dimensions give a hydraulic diameter of $D_{\mathrm{h}}=38.05 \mathrm{~mm}$ and $D_{\mathrm{h}}=5.67 \mathrm{~mm}$, respectively. In each case, the length of the overall channel or matrix module is $L=135 \mathrm{~mm}$.

The four geometries are characterized by two different values of rib height $h_{\text {rib }}: 15$ and $1.5 \mathrm{~mm}$. For each rib height, two different configurations have been studied: one having four entry channels and lower rib thickness $t_{\mathrm{rib}}=1.5 \mathrm{~mm}$, one having six entry channels and higher rib thickness $t_{\text {rib }}=3.0 \mathrm{~mm}$. This results in two different open area values: $R_{\mathrm{vp}}=84.5 \%$ for $01-03$ geometries and $R_{\mathrm{vp}}=53.5 \%$ for $02-04$ geometries.

Moving from Geom 01 to Geom 04 the values of subchannel hydraulic diameter $d_{\mathrm{h}, \mathrm{s}}$ decrease with the increasing of rib thickness $t_{\text {rib }}$ and number of subchannels $n_{\text {can }}$ and with the reduction of rib height $h_{\text {rib }}$.

It must be pointed out that the geometries selected for this experimental investigation are representative of extreme cases; in fact, two geometries (Geom 01, 02) are suitable for an application in the mid chord region, while the other two geometries (Geom $03,04)$ are suitable for the trailing edge region of a gas turbine airfoil. Moreover, for each of these two cases, it is possible to investigate the combined effects of an increase of rib thickness and number of subchannels resulting in an extreme reduction of flow passage area.

2.4 Data Reduction. Heat transfer tests were performed using a steady state technique. In this study, two HTCs with a different physical meaning were determined: $h \mathrm{cc}_{\mathrm{eq}}$ and $h \mathrm{c}_{\mathrm{r}}$. The first $\left(\mathrm{htc}_{\mathrm{eq}}\right)$ is an equivalent value that includes both heat transfer term due to rib/fin surface and effective term applicable on the rib surfaces, while the second $\left(h_{t} c_{r}\right)$ represents the effective average HTC value that derives from the heat transfer between fluid and rib and it is applicable to the rib surfaces. The htc $\mathrm{eq}_{\mathrm{eq}}$ values are representative of an overall heat transfer and could be useful for industrial design purposes, while htc $\mathrm{r}_{\mathrm{r}}$ values could be used to find out correlations about the influence of the regime flow on heat transfer performance.

Starting from the Newton's law of cooling, htc $\mathrm{eq}_{\mathrm{eq}}$ values are calculated at the base of the rib according to the following relation:

$$
\text { htc }_{\mathrm{eq}, i}=\frac{Q_{\text {input }, i}-Q_{\text {loss }, i}-Q_{\text {cond }, \text { lat }, i}}{A_{\mathrm{b}} \cdot\left(T_{\mathrm{w}, \mathrm{sup}, i}-T_{\mathrm{air}, i}\right)} ; \quad i=1,5
$$

where $A_{\mathrm{b}}=W_{\mathrm{b}}^{2}$ is the base area of the element, $T_{\mathrm{air}, i}$ is the average air temperature while $T_{\mathrm{w}, \text { sup }, i}$ represents the wall temperature at the base of the rib.
As regards the heat terms, $Q_{\text {input }, i}$ represents the power supplied by each heater, $Q_{\text {loss }, i}$ is the heat lost from each matrix block while $Q_{\text {cond,lat, } i}$ is the heat transferred from the $i$ th block to those adjacents; the latter is expressed as

$$
Q_{\text {cond,lat }, i}=A_{\text {lat }} \cdot \frac{k_{\text {is }}}{s_{\text {is }}} \cdot\left(2 T_{\mathrm{w}, i}-T_{\mathrm{w}, i-1}-T_{\mathrm{w}, i+1}\right)
$$

where $A_{\text {lat }}=W_{\mathrm{b}} \cdot h_{\mathrm{b}}$ is the lateral contact area between two adjacent blocks. Details on heat losses $Q_{\mathrm{loss}, i}$ determination are given in Sec. 2.5.

The $T_{\mathrm{w}, \mathrm{sup}, i}$ is evaluated starting from the temperature value $T_{\mathrm{w}, i}$, which is the local wall temperature measured by the thermocouple at a given distance $h_{\mathrm{TC}}$ from the base of the block, and considering an energy balance of heat fluxes for each matrix block (Fig. 6). In particular, the solution of the second-order differential heat equation provides the $T_{\mathrm{w}, i}(x)$ distribution along the thickness of the matrix module

$$
k \cdot \frac{d^{2} T}{d x^{2}}=\frac{Q_{\text {cond }, \text { lat }, i}}{A_{\text {lat }}}
$$

To solve this equation the two following boundary conditions are considered:

$$
\begin{gathered}
T_{\mathrm{w}, i}\left(x=h_{\mathrm{TC}}\right)=T_{\mathrm{w}, i} \\
\left.k \cdot \frac{d T}{d x}\right|_{x=0}=\frac{Q_{\text {input }, i}-Q_{\text {loss }, i}}{A_{\mathrm{b}}}
\end{gathered}
$$

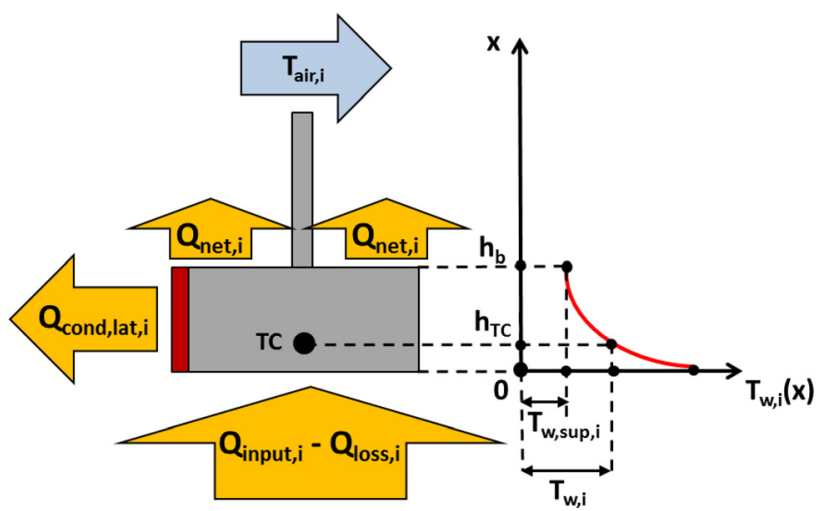

Fig. 6 Heat fluxes and wall temperature distribution through a single matrix block 
where the first is specified in terms of the temperature $T_{\mathrm{w}, i}$ measured by the thermocouple at $x=h_{\mathrm{TC}}$, while the second corresponds to the net input power supplied at the base of the matrix module $x=0$. In this way $T_{\mathrm{w}, i}\left(x=h_{\mathrm{b}}\right)=T_{\mathrm{w}, \text { sup }, i}$, which is the desired temperature value at the base of the rib, is evaluated.

On the other hand, htc ${ }_{\mathrm{r}}$, which is the applicable value on the rib surfaces, is calculated by applying the fin effectiveness theory [10]; in this case, especially for geometries with smaller rib height, the surface at the tip is not treated as adiabatic because the heat transfer at the rib tip is not negligible compared to the other heat transfer surfaces. According to this assumption, the heat transferred from the base of the rib can be evaluated as

$$
q_{\mathrm{f}}=\sqrt{\mathrm{htc}_{\mathrm{r}} P k_{\mathrm{met}} A_{\mathrm{c}}} \cdot \theta_{\mathrm{b}} \cdot \frac{\sinh (m L)+\left(h t c_{\mathrm{r}} / m k_{\mathrm{met}}\right) \cosh (m L)}{\cosh (m L)+\left(h t c_{\mathrm{r}} / m k_{\mathrm{met}}\right) \sinh (m L)}
$$

where $m$ is the fin parameter $\left(\mathrm{htc}_{\mathrm{r}} \cdot A_{\mathrm{c}} / k_{\mathrm{met}} \cdot P\right)^{0.5}[10]$.

Then, since the overall heat exchanged by convection is given by the sum of heat transfer term due to ribbed areas $\left(q_{\mathrm{f}}\right)$ and heat transfer term due to non ribbed areas, the following balance equation can be written:

$$
q_{\mathrm{f}}+\operatorname{htc}_{\mathrm{r}, i} W_{\mathrm{c}} L_{\mathrm{rib}}\left(T_{\mathrm{w}, \mathrm{sup}, i}-T_{\mathrm{air}, i}\right)=\operatorname{htc}_{\mathrm{eq}, i} A_{\mathrm{b}}\left(T_{\mathrm{w}, \text { sup }, i}-T_{\mathrm{air}, i}\right)
$$

Therefore, knowing htc $\mathrm{eq}, i$ values and using Eqs. (6) and (7), htc $_{\mathrm{r}, i}$ coefficients are determined through an iterative cycle.

For both cases, the HTCs are calculated in a condition as close as possible to the Biot number similitude with the real application; for this reason, AISI 304 stainless steel with a thermal conductivity $k_{\mathrm{met}}=15.1 \mathrm{~W} / \mathrm{mK}$ has been selected for the manufacturing of matrix geometries.

2.5 Heat Losses Determination. The heat losses are determined from several calibration tests with the test-article closed to avoid any air circulation. The heat supplied by the heaters was set in order to reach a series of given temperature values and then recorded. The power supplied to the heaters during this calibration is equivalent to the heat lost during the actual measurement due to the heat conducted through the thermal insulating shell. For each calibration test, an energy balance can be written for each block

$$
\begin{aligned}
Q_{\text {input }, i}= & Q_{\text {loss }, i}+\frac{k_{\text {is }}}{s_{\text {is }}} \cdot\left(W_{\mathrm{b}} \cdot h_{\mathrm{b}}\right) \cdot\left(T_{\mathrm{w}, i}-T_{\mathrm{w}, i-1}\right) \\
& +\frac{k_{\mathrm{is}}}{s_{\mathrm{is}}} \cdot\left(W_{\mathrm{b}} \cdot h_{\mathrm{b}}\right) \cdot\left(T_{\mathrm{w}, i}-T_{\mathrm{w}, i+1}\right) ; \quad i=1,5
\end{aligned}
$$

The heat loss can be modeled as a function of block temperature respect to ambient temperature $T_{\mathrm{amb}}$ and so it can be expressed as a polynomial function

$$
\begin{aligned}
Q_{\text {input }, i}= & {\left[a_{\text {loss }, i}+b_{\text {loss }, i} \cdot\left(T_{\mathrm{w}, i}-T_{\mathrm{amb}}\right)+c_{\text {loss }, i} \cdot\left(T_{\mathrm{w}, i}-T_{\mathrm{amb}}\right)^{2}\right] } \\
& +\frac{k_{\mathrm{is}}}{s_{\mathrm{is}}} \cdot\left(W_{\mathrm{b}} \cdot h_{\mathrm{b}}\right) \cdot\left(2 T_{\mathrm{w}, i}-T_{\mathrm{w}, i-1}-T_{\mathrm{w}, i+1}\right) ; \quad i=1,5
\end{aligned}
$$

If $m$ calibration tests are run then $(m \cdot 5)$ equations can be written where the unknowns are $a_{\mathrm{loss}, i}, b_{\mathrm{loss}, i}, c_{\mathrm{loss}, i}$ and $k_{\mathrm{is}}$. These coefficients can be determined using linear least squares approach. Generally, $\quad a_{\mathrm{loss}, i}=0$ because if $\left(T_{\mathrm{w}, I}-T_{\mathrm{amb}}\right)=0$ then also $Q_{\text {loss }, i}=0$.

2.6 Experimental Procedure and Test Conditions. Before starting the experiment, the total mass flow rate $\dot{m}_{\text {air }}$, corresponding to the subchannel Reynolds number $\mathrm{Re}_{\mathrm{s}}$, is set by changing the speed of the pumps and regulating the throttle valve located downstream the test section. Power is supplied by the heaters; a condition of constant heat flux is reached by varying the power input to each foil heater attached to each steel block. The test model is allowed to reach thermal steady state before experimental data are collected.

The local regional wall temperature $T_{\mathrm{w}, i}$ is directly measured using the thermocouple installed in the blind hole on each metallic plate. The temperature of each plate is assumed uniform because the thermocouples are located at a depth where the temperature distortion for fin is negligible; this latter hypothesis has been verified by means of thermal finite element method (FEM) calculations.

Starting from the air temperature measured at the inlet $T_{\text {air,in }}$, the local bulk air temperature $T_{\mathrm{air}, i}$ at any streamwise location along the test model can be calculated at the midpoint of each steel plate using an energy balance equation as

$$
\begin{aligned}
T_{\mathrm{air}, i}=T_{\mathrm{air}, i n}+\frac{\left(\sum_{j=1}^{i-1}\left(Q_{\mathrm{net}, j}\right)_{\mathrm{up}}+\frac{1}{2}\left(Q_{\mathrm{net}, i}\right)_{\mathrm{up}}\right)}{\dot{m}_{\mathrm{air}} \cdot c_{\mathrm{p}, \text { air }}}+ \\
+\frac{\left(\sum_{j=1}^{i-1}\left(Q_{\mathrm{net}, j}\right)_{\mathrm{low}}+\frac{1}{2}\left(Q_{\mathrm{net}, i}\right)_{\text {low }}\right)}{\dot{m}_{\mathrm{air}} \cdot c_{\mathrm{p}, \text { air }}}
\end{aligned}
$$

where $Q_{\text {net }, i}=Q_{\text {input }, i}-Q_{\text {loss }, i}-Q_{\text {cond,lat }, i}$ is the net heat from the $i$ th steel plate to the cooling air. The bulk air temperature $T_{\text {air, } 6}$, calculated at the outlet of the test section, is then compared with the measured one $T_{\text {air,out }}$ to ensure that a steady state condition is reached and that $Q_{\text {loss }}$ are correctly evaluated.

The main investigated parameters $\mathrm{Re}_{\mathrm{s}}$ and $\mathrm{Nu}_{\mathrm{s}}$ are defined as follows:

$$
\begin{gathered}
\operatorname{Re}_{\mathrm{s}}=\frac{\dot{m}_{\mathrm{air}} \cdot d_{\mathrm{h}, \mathrm{s}}}{A_{\mathrm{can}} \cdot n_{\mathrm{can}} \cdot \mu_{\mathrm{air}, \text { in }}} \\
\mathrm{Nu}_{\mathrm{s}}=\frac{\mathrm{htc} \cdot d_{\mathrm{h}, \mathrm{s}}}{k_{\mathrm{air}, \text { in }}}
\end{gathered}
$$

where $d_{\mathrm{h}, \mathrm{s}}$ and $A_{\text {can }}$ are the hydraulic diameter and cross-sectional area of the subchannel, respectively. Thermophysical properties of the air $\left(\mu_{\mathrm{air}, \text { in }}\right.$ and $\left.k_{\mathrm{air}, \text { in }}\right)$ are calculated from pressure and temperature values measured at the inlet of the test section. Average Nusselt numbers have been evaluated according to the above mentioned definitions of HTCs: $\mathrm{Nu}_{\mathrm{eq}, \mathrm{s}}$ and $\mathrm{Nu}_{\mathrm{r}, \mathrm{s}}$ from htc $\mathrm{eq}_{\mathrm{eq}}$ and $\mathrm{htc}_{\mathrm{r}}$ values, respectively.

2.7 Experimental Uncertainty. An uncertainty analysis was performed following the ASME [11] standard based on Kline and McClintock's [12] method. The maximum uncertainty in the evaluation of Nusselt number is approximately 6\%; it derives mostly from the uncertainty in power input, heat losses, and temperature of thermocouples.

\section{Results}

3.1 Pressure Loss. Figure 7 shows the locations of the static pressure taps for one matrix geometry. Values are measured along four different subchannels tracks from the inlet to the outlet of each test model. Since the pressure measurements are very similar along the four tracks, only pressure values of track 1 are shown. Figure 8 shows the pressure drop in terms of pressure ratios from the ambient pressure $p_{\mathrm{amb}}$ with the increasing of $\mathrm{Re}_{\mathrm{s}}$ number.

Data in Fig. 8 are referred to the geometry with the lowest value of hydraulic diameter (Geom 04), while the same values for Geom 01 and Geom 02 (maximum rib height) fall into the range $p / p_{\mathrm{amb}}=0.94-1$. The average friction factor $f$ is calculated as

$$
f=\frac{\Delta p \cdot d_{\mathrm{h}, \mathrm{s}}}{4 \cdot L_{\mathrm{tot}} \cdot 1 / 2 \cdot \rho \cdot v_{\mathrm{in}}^{2}}
$$




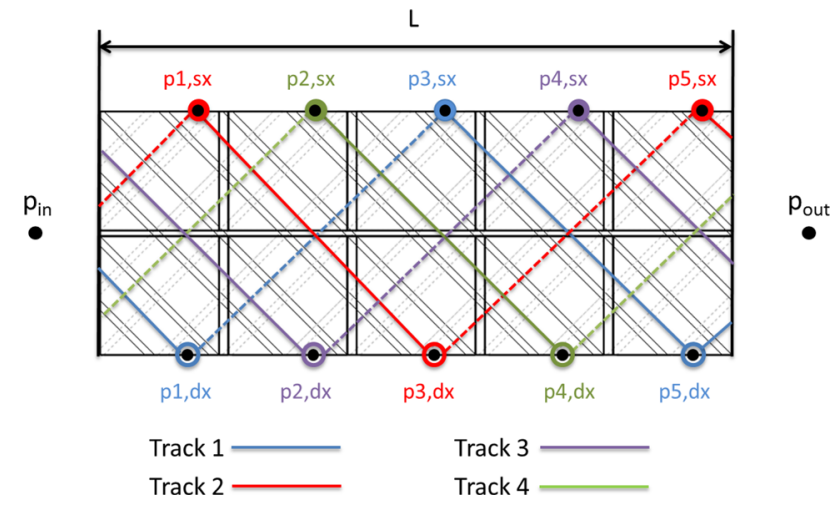

Fig. 7 Pressure taps locations along different subchannel tracks

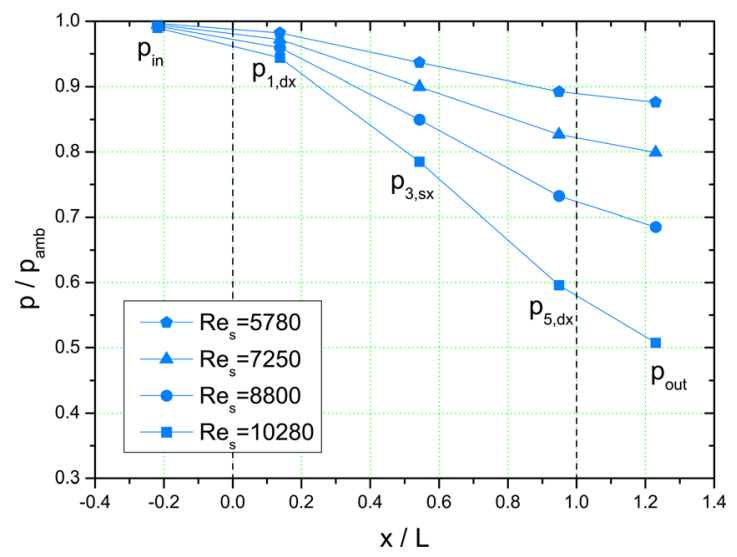

Fig. 8 Pressure ratios distribution along track 1

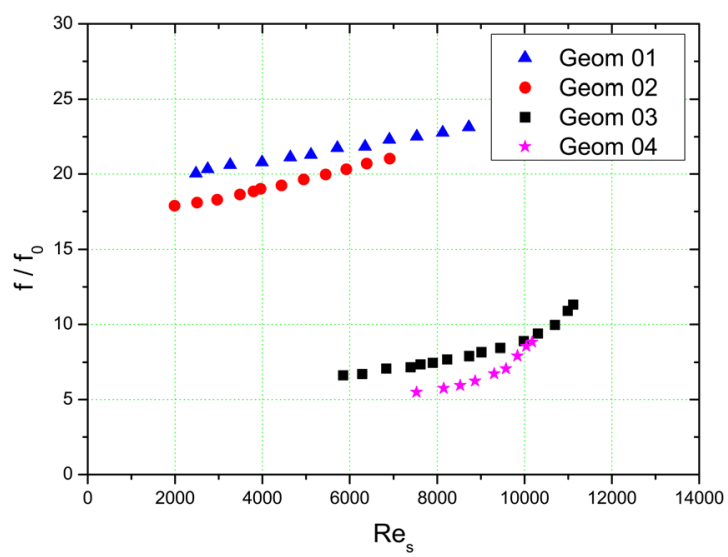

Fig. 9 Normalized friction factor $\left(f / f_{0}\right)$ for different $\mathrm{Re}_{\mathrm{s}}$

where $\Delta p$ represents the overall pressure drop through the model, while $L_{\text {tot }}$ is the overall distance of the flow along a track.

Figure 9 shows the friction factor ratio $\left(f / f_{0}\right)$ as a function of $\operatorname{Re}_{\mathrm{s}}$, where $f_{0}$ is the friction factor of a fully developed turbulent flow in a smooth duct and is calculated according the KarmanNikuradse equation

$$
f_{0}=0.046 \cdot \mathrm{Re}_{\mathrm{s}}^{-0.2}
$$

The significant increase of $\left(f / f_{0}\right)$ at higher Reynolds values for Geom 03 and especially for Geom 04 (Fig. 9) is due to the very high Mach number, which is close to one at the outlet section.
3.2 Heat Transfer. Figure 10 presents the equivalent Nusselt number $\mathrm{Nu}_{\mathrm{eq}, \mathrm{s}}$ averaged on all matrix elements of the model as a function of $\mathrm{Re}_{\mathrm{s}}$; these values are calculated from htc $\mathrm{eq}_{\mathrm{eq}}$ values and are divided by $\mathrm{Nu}_{\mathrm{ref}}$ that represents the equivalent Nusselt number reference value at the minimum Reynolds number for the geometry with the highest passage area (Geom 01 ).

An increase of subchannels number and rib thickness does not produce a significant effect on the averaged Nusselt number. On the other hand, a strong decrease of rib height, for example, moving from Geom 01 to Geom 03 or from Geom 02 to Geom 04 reduces to half the heat transfer performance $\mathrm{Nu}_{\mathrm{eq}, \mathrm{s}} / \mathrm{Nu}_{\mathrm{ref}}$; this is mainly due to the reduction of heat transfer surface. A Reynolds number dependence appears for each case; in fact, $\mathrm{Nu}_{\text {eq,s }}$ values have a noticeable increase with the increasing of $\mathrm{Re}_{\mathrm{s}}$.

Since at each streamwise location four steel elements are used, two for the upper module and two for the lower one, average $\mathrm{Nu}_{\text {eq,s }}$ values can be also obtained for each streamwise block. Figure 11 shows the streamwise $\mathrm{Nu}_{\text {eq, }} / \mathrm{Nu}_{\text {ref }}$ distributions as a function of the streamwise position at the same flow rate condition. It can be observed that heat transfer is quite uniform from the inlet to the exit for each matrix geometry.

Figures 12 and 13 show the average enhancement factor $\mathrm{Nu}_{\mathrm{r}, \mathrm{s}} /$ $\mathrm{Nu}_{0}$ as a function of subchannel Reynolds number; the average Nusselt number is normalized by the Dittus-Boelter correlation

$$
\mathrm{Nu}_{0}=0.023 \cdot \operatorname{Re}_{\mathrm{s}}^{0.8} \cdot \operatorname{Pr}^{0.4}
$$

The same plots also depict a comparison between present data and other experimental results found in literature [7] and [8]. In

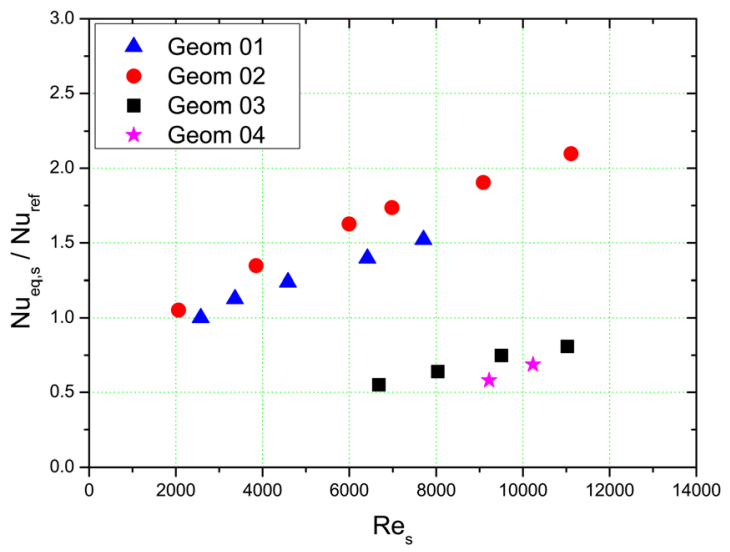

Fig. 10 Subchannel averaged Nusselt numbers $\mathrm{Nu}_{\text {eq,s }}$ for different $\mathbf{R e}_{\mathrm{s}}$

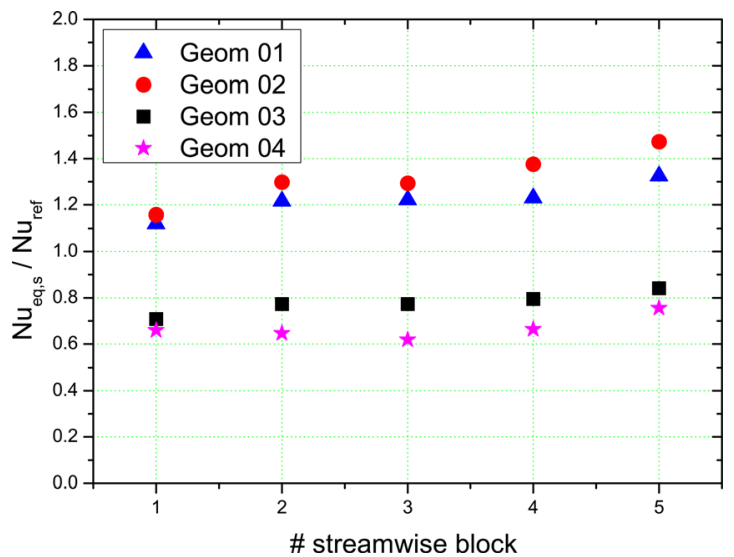

Fig. 11 Subchannel averaged Nusselt numbers $\mathrm{Nu}_{\mathrm{eq}, \mathrm{s}}$ as a function of streamwise location at the same mass flow rate 


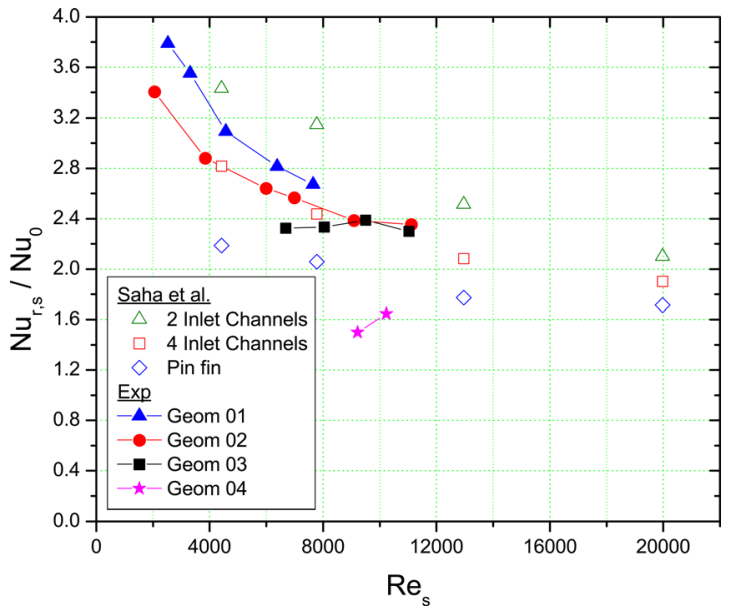

Fig. $12 \mathrm{Nu}_{\mathrm{r}, \mathrm{s}} / \mathrm{Nu}_{0}$ comparison with Saha et al. [7] for different $\mathrm{Re}_{\mathrm{s}}$

this case, average Nusselt numbers are calculated from htc $\mathrm{r}_{\mathrm{r}}$ values instead of htc $\mathrm{eq}_{\mathrm{eq}}$ ones. From this comparison, it is clear that present $\mathrm{Nu}_{\mathrm{r}, \mathrm{s}} / \mathrm{Nu}_{0}$ values are in line with other previous works; moreover, as regards geometries with higher ribs (Geom 01, 02), values in Fig. 12 follow the same trend of geometries with 2 and 4 inlet channels [7]. A common feature that has been found from this comparison is that matrix geometries with a lower number of subchannels performs better in terms of heat transfer enhancement $\mathrm{Nu}_{\mathrm{r}, \mathrm{s}} / \mathrm{Nu}_{0}$; in fact, for the same Reynolds number, geometry with four subchannels (Geom 01) has higher values than the other with six subchannels (Geom 02). These results also highlight that the heat transfer augmentation decreases slightly with an increasing in Reynolds number.

On the other hand, geometries with the lowest rib height (Geom 03, 04) seems to have a different behavior; $\mathrm{Nu}_{\mathrm{r}, \mathrm{s}} / \mathrm{Nu}_{0}$ trend for Geom 03 is not affected by Reynolds number but its $\mathrm{Re}_{\mathrm{s}}$ investigated range, especially for low values, is not exactly comparable to other 01 and 02 geometries. Values for Geom 04 are lower, but the limited number of experiments done is not enough to identify a trend. Such limitation was due on one side to the minimum measurable mass flow rate, while on the other side to the very high pressure losses achieved.

Finally, Fig. 13 reports the comparison with experimental data from a publication of Acharya et al. [8], which investigated a

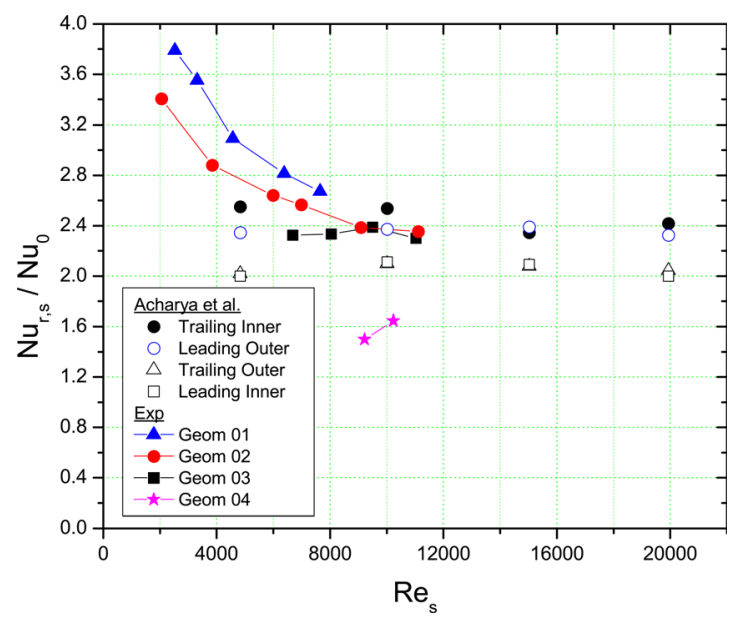

Fig. $13 \mathrm{Nu}_{\mathrm{r}, \mathrm{s}} / \mathrm{Nu}_{0}$ comparison with Acharya et al. [8] for different $\mathrm{Re}_{\mathrm{s}}$

Journal of Turbomachinery

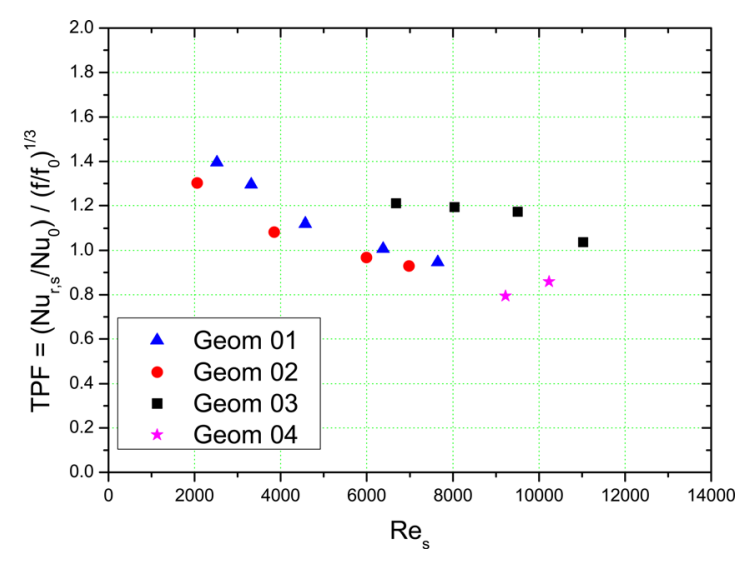

Fig. 14 TPF comparison

similar geometry at the same Reynolds values. The trend of present results is in line with literature data at higher Reynolds values, while there are some discrepancies at lower values.

A TPF has been calculated as

$$
\mathrm{TPF}=\frac{\left(\mathrm{Nu}_{\mathrm{r}, \mathrm{s}} / \mathrm{Nu}_{0}\right)}{\left(f / f_{0}\right)^{1 / 3}}
$$

For geometries with higher rib heights (Geom 01, 02) the TPF falls into the range of 0.94-1.4, while TPF values for the other two geometries (Geom 03, 04) varies from 0.85 to 1.2 (Fig. 14).

\section{Conclusions}

The present experimental study has been performed to investigate the heat transfer and pressure drop in lattice-matrix geometries with crossing angle of $45 \mathrm{deg}$ between ribs. The effects of rib height, rib thickness and number of subchannels have been investigated varying the $\mathrm{Re}_{\mathrm{s}}$, based on subchannel hydraulic diameter, from 2000 to 12,000 .

HTCs have been measured using a steady state technique in a condition as close as possible to the Biot number similitude with real application.

The following conclusions have been obtained:

(1) Pressure drop rises along the streamwise direction with the increasing of Reynolds number. The overall friction factor also increases with increasing Reynolds number for each studied case.

(2) Keeping constant rib height, the average Nusselt number is not very affected by a variation of rib thickness and of subchannels number. On the other hand, a strong reduction of rib height (1/10 ratio) reduces to half the heat transfer performance and such effect is mainly due to rib surface decrease.

(3) Very uniform streamwise distributions have been found in terms of average Nusselt number from the inlet to the exit of each geometry. Values are slightly lower in the entrance region of the test model because of the absence of flow turning and turbulence.

(4) Heat transfer enhancement values $\mathrm{Nu}_{\mathrm{r}, \mathrm{s}} / \mathrm{Nu}_{0}$ are higher than 2.5 for $\operatorname{Re}_{\mathrm{s}}<6000$ and vary from 2.0 to 2.5 for $\operatorname{Re}_{\mathrm{s}}>6000$. This enhancement factor decreases slightly with an increase of Reynolds number. These results agree with the experimental results of other previous works about lattice-matrix geometries.

(5) A TPF of 0.94-1.4 has been obtained for geometries with higher rib height, while TPF values for geometries with lower rib height are slightly lower because of the higher pressure losses. 


\section{Nomenclature}

$A=$ cross-sectional area $\left(\mathrm{mm}^{2}\right)$

$A_{\mathrm{b}}=$ base area of single matrix element $\left(\mathrm{mm}^{2}\right)$

$A_{\mathrm{c}}=$ cross-sectional area of fin or rib $\left(\mathrm{mm}^{2}\right)$

$A_{\text {lat }}=$ contact area between adjacent matrix elements $\left(\mathrm{mm}^{2}\right)$

A.R. $=$ cross-sectional area aspect ratio

$c_{\mathrm{p}}=$ specific heat $(\mathrm{J} / \mathrm{kg} \mathrm{K})$

$d_{\mathrm{h}, \mathrm{s}}=$ subchannel cross section hydraulic diameter $(\mathrm{mm})$

$D_{\mathrm{h}}=$ overall cross section hydraulic diameter $(\mathrm{mm})$

$f=$ average friction factor

$f_{0}=$ average friction factor for a smooth tube

$H=$ overall cross section height $(\mathrm{mm})$

$h_{\mathrm{b}}=$ thickness of the matrix module without ribs (mm)

$h_{\text {rib }}=$ rib height $(\mathrm{mm})$

$h_{\mathrm{TC}}=$ distance base of matrix blocks-thermocouple hole (mm)

$h_{t} c_{\mathrm{eq}}=$ equivalent heat transfer coefficient $\left(\mathrm{W} /\left(\mathrm{m}^{2} \mathrm{~K}\right)\right)$

$\mathrm{htc}_{\mathrm{r}}=$ heat transfer coefficient on the rib surfaces $\left(\mathrm{W} /\left(\mathrm{m}^{2} \mathrm{~K}\right)\right)$

$k=$ thermal conductivity $(\mathrm{W} /(\mathrm{m} \mathrm{K}))$

$k_{\text {is }}=$ thermal conductivity of insulation spacers $(\mathrm{W} /(\mathrm{m} \mathrm{K}))$

$k_{\mathrm{met}}=$ thermal conductivity of steel matrix blocks $(\mathrm{W} /(\mathrm{m} \mathrm{K}))$

$l=$ average length of subchannels between side walls $(\mathrm{mm})$

$L=$ matrix module length $(\mathrm{mm})$

$L_{\text {rib }}=$ overall length of rib for each matrix block (mm)

$L_{\text {tot }}=$ overall length of a subchannel (mm)

$m=$ fin parameter $\left(\mathrm{htc}_{\mathrm{r}} \cdot A_{\mathrm{c}} / k_{\mathrm{met}} \cdot P\right)^{0.5}$

$\dot{m}=$ mass flow rate $(\mathrm{kg} / \mathrm{s})$

$n_{\text {can }}=$ number of subchannels

$\mathrm{Nu}=$ Nusselt number

$\mathrm{Nu}_{\mathrm{eq}}=$ Nusselt number evaluated from htc $\mathrm{eq}_{\mathrm{eq}}$ values

$\mathrm{Nu}_{\mathrm{r}}=$ Nusselt number evaluated from htc $\mathrm{r}_{\mathrm{r}}$ values

$\mathrm{Nu}_{\mathrm{s}}=$ subchannel Nusselt number

$\mathrm{Nu}_{0}=$ smooth tube Nusselt number

$p=$ pressure $(\mathrm{Pa})$

$P=$ fin perimeter $(\mathrm{mm})$

$\operatorname{Pr}=$ Prandtl number

$Q_{\text {cond }}=$ heat transferred by conduction (W)

$q_{\mathrm{f}}=$ heat transferred from the base of the rib (W)

$Q_{\text {input }}=$ power supplied by etched foil heaters (W)

$Q_{\text {loss }}=$ heat losses (W)

$Q_{\text {net }}=$ net heat $(\mathrm{W})$

$R_{\mathrm{vp}}=$ open area ratio $(\%) \mathrm{R}_{\mathrm{vp}}=\left(\mathrm{W}_{\mathrm{c}} /\left(\mathrm{W}_{\mathrm{c}}+\mathrm{t}_{\mathrm{rib}}\right)\right)$

$\mathrm{Re}=$ Reynolds number

$\mathrm{Re}_{\mathrm{s}}=$ Reynolds number at the inlet of a subchannel

$\mathrm{s}_{\mathrm{is}}=$ thickness of insulation spacers $(\mathrm{mm})$

$T=$ temperature $(\mathrm{K})$

$T_{\text {air }}=$ air temperature $(\mathrm{K})$

$t_{\text {rib }}=$ rib thickness $(\mathrm{mm})$

$T_{\mathrm{w}}=$ wall local temperature measured by thermocouple (K)

$T_{\mathrm{w} \text {,sup }}=$ wall temperature at the base of ribs $(\mathrm{K})$

$v=$ air velocity in the subchannel $(\mathrm{m} / \mathrm{s})$

$W=$ overall cross section width $(\mathrm{mm})$

$W_{\mathrm{b}}=$ width of single matrix block $(\mathrm{mm})$

$W_{\mathrm{c}}=$ subchannel width $(\mathrm{mm})$

$W_{\mathrm{i}}=$ subchannel inlet width $(\mathrm{mm})$

$\Delta p=$ pressure drop $(\mathrm{Pa})$

\section{Greek Symbols}

$\beta=$ subchannel inclination angle (deg) $\mu=$ dynamic viscosity $(\mathrm{Pa} \cdot \mathrm{s})$
$\rho=\operatorname{density~}\left(\mathrm{kg} / \mathrm{m}^{3}\right)$

\section{Subscripts}

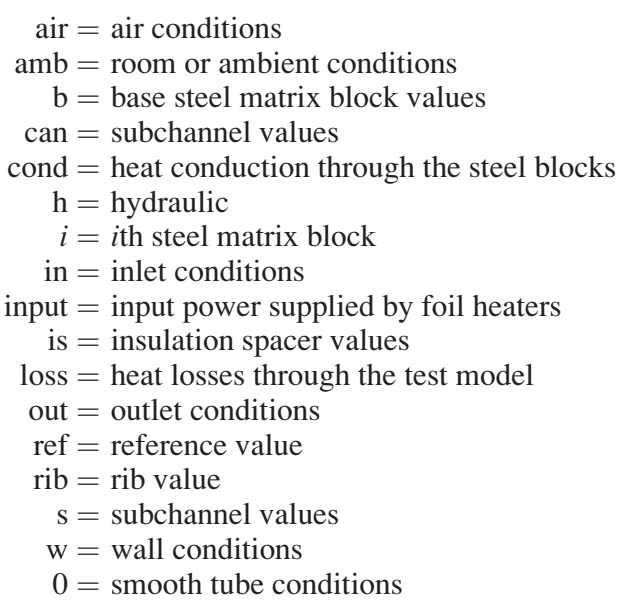

\section{Acronyms}

$\mathrm{FEM}=$ finite element method

$\mathrm{HTC}=$ heat transfer coefficient

PMMA $=$ polymethyl methacrylate

TIT $=$ turbine inlet temperature

$\mathrm{TPF}=$ thermal performance factor

\section{References}

[1] Goreloff, V., Goychengerg, M., and Malkoff, V., 1990, "The Investigation of Heat Transfer in Cooled Blades of Gas Turbines," AIAA Paper No. 90-2144.

[2] Nagoga, G., 1996, Effective Methods of Cooling of Blades of High Temperature Gas Turbines, Publishing House of Moscow Aerospace Institute, Moscow, p. 100.

[3] Sundberg, J., 2006, The Heat Transfer Correlations for Gas Turbine Cooling, Linköping University, Linköping, Sweden, pp. 38-63.

[4] Gillespie, D. R. H., Ireland, P. T., and Dailey, G. M., 2000, "Detailed Flow and Heat Transfer Coefficient Measurements in a Model of an Internal Cooling Geometry Employing Orthogonal Intersecting Channels," ASME Turbo Expo, Munich, Germany, May 8-11, ASME Paper No. 2000-GT-653.

[5] Bunker, R. S., 2004, "Latticework (Vortex) Cooling Effectiveness Part 1: Stationary Channel Experiments," ASME Turbo Expo, Vienna, Austria, June 14-17, ASME Paper No. GT2004-54127.

[6] Saha, K., Guo, S., Acharya, S., and Nakamata, C., 2008, "Heat Transfer and Pressure Measurements in a Lattice-Cooled Trailing Edge of a Turbine Airfoil," ASME Turbo Expo, Berlin, Germany, June 9-13, ASME Paper No. GT200851324.

[7] Saha, K., Acharya, S., and Nakamata, C., 2013, "Heat Transfer Enhancement and Thermal Performance of Lattice Structures for Internal Cooling of Airfoil Trailing Edges," ASME J. Therm. Sci. Eng. Appl., 5(1), p. 011001.

[8] Acharya, S., Zhou, F., Lagrone, J., Mahmood, G., and Bunker, R., 2004, "Latticework (Vortex) Cooling Effectiveness Part 2: Rotating Channel Experiments," ASME Turbo Expo, Vienna, Austria, June 14-17, ASME Paper No. GT2004-53983.

[9] Oh, I. T., Kim, K. M., Lee, D. H., Park, J. S., and Cho, H. H., 2009, "Local Heat/Mass Transfer and Friction Loss Measurement in a Rotating Matrix Cooling Channel," ASME Turbo Expo, Orlando, FL, June 8-12, ASME Paper No. GT2009-59873.

[10] Incropera, F. P., and DeWitt, D. P., 1996, Fundamentals of Heat and Mass Transfer, 4th ed., Wiley, Hoboken, NJ.

[11] ASME, 1985, "Measurement Uncertainty," Instrument and Apparatus, Part 1: Performance Test Codes, ASME, New York.

[12] Kline, S. J., and McClintock, F. A., 1953, "Describing Uncertainties in Single Sample Experiments," ASME J. Mech. Eng., 75(1), pp. 3-8. 